\title{
Glucagon-like peptide I receptor stimulation reverses key deficits in distinct rodent models of Parkinson's disease
}

\author{
Alexander Harkavyi ${ }^{1}$, Amjad Abuirmeileh ${ }^{1}$, Rebecca Lever ${ }^{1}$, \\ Ann E Kingsbury ${ }^{2}$, Christopher S Biggs ${ }^{3}$ and Peter S Whitton*1
}

\begin{abstract}
Address: ${ }^{1}$ Department of Pharmacology, The School of Pharmacy, 29-39 Brunswick Square, London WC1N 1AX, UK, ${ }^{2}$ Rita Lila Weston Institute of Neurological Studies, 1 Wakefield Street, London WC1N 1PJ, UK and ${ }^{3}$ School of Biosciences, University of Westminster, 115 New Cavendish Street, London W1W 6UW, UK

Email: Alexander Harkavyi - alexander.harkavyi@pharmacy.ac.uk; Amjad Abuirmeileh - amjad.abuirmeileh@pharmacy.ac.uk; Rebecca Lever - rebecca.lever@pharmacy.ac.uk; Ann E Kingsbury - ann.kingsbury@ion.ucl.ac.uk; Christopher S Biggs - biggsc@wmin.ac.uk; Peter S Whitton* - peter.whitton@pharmacy.ac.uk

* Corresponding author
\end{abstract}

Published: 2I May 2008

Journal of Neuroinflammation 2008, 5:19 doi:10.1186/1742-2094-5-19
Received: 4 March 2008

Accepted: 21 May 2008

This article is available from: http://www.jneuroinflammation.com/content/5/1/19

(C) 2008 Harkavyi et al; licensee BioMed Central Ltd.

This is an Open Access article distributed under the terms of the Creative Commons Attribution License (http://creativecommons.org/licenses/by/2.0), which permits unrestricted use, distribution, and reproduction in any medium, provided the original work is properly cited.

\begin{abstract}
Background: It has recently become apparent that neuroinflammation may play a significant role in Parkinson's disease (PD). This is also the case in animal paradigms of the disease. The potential neuroprotective action of the glucagon-like peptide I receptor (GLP-IR) agonist exendin-4 (EX-4), which is protective against cytokine mediated apoptosis and may stimulate neurogenesis, was investigated In paradigms of PD.

Methods: Two rodent 'models' of PD, 6-hydroxydopamine (6-OHDA) and lipopolysaccaride (LPS), were used to test the effects of EX-4. Rats were then investigated in vivo and ex vivo with a wide range of behavioural, neurochemical and histological tests to measure integrity of the nigrostriatal system.

Results: EX-4 ( 0.1 and $0.5 \mu g / \mathrm{kg})$ was given seven days after intracerebral toxin injection. Seven days later circling behaviour was measured following apomorphine challenge. Circling was significantly lower in rats given EX-4 at both doses compared to animals given 6-OHDA/LPS and vehicle. Consistent with these observations, striatal tissue DA concentrations were markedly higher in 6-OHDA/LPS + EX-4 treated rats versus 6-OHDA/LPS + vehicle groups, whilst assay of L-DOPA production by tyrosine hydroxylase was greatly reduced in the striata of 6-OHDA/LPS + vehicle rats, but this was not the case in rats coadministered EX-4. Furthermore nigral TH staining recorded in 6-OHDA/LPS + vehicle treated animals was markedly lower than in sham-operated or EX-4 treated rats. Finally, EX-4 clearly reversed the loss of extracellular DA in the striata of toxin lesioned freely moving rats.

Conclusion: The apparent ability of EX-4 to arrest progression of, or even reverse nigral lesions once established, suggests that pharmacological manipulation of the GLP-I receptor system could have substantial therapeutic utility in PD. Critically, in contrast to other peptide agents that have been demonstrated to possess neuroprotective properties in pre-clinical models of PD, EX-4 is in current clinical use in the management of type-II diabetes and freely crosses the blood brain barrier; hence, assessment of the clinical efficacy of EX-4 in patients with PD could be pursued without delay.
\end{abstract}




\section{Background}

The well-characterised features of Parkinson's disease (PD) are largely the result of a selective degeneration of nigrostriatal neurons, greatly reduced synthetic capacity for dopamine and a consequent failure to engage striatal dopamine receptors [1]. Before the disease presents clinically, death of nigrostriatal neurons occurs in the substantia nigra pars compacta (SNc) 'silently', probably as a result of concurrent apoptotic, excitotoxic, free-radical mediated and neuroinflammatory events [2-5]. Environmental and toxicological factors including bacterial toxins, in addition to the expression of candidate 'Parkinsonian' genes have all been proposed in the aetiology of the disease $[2,3,5]$. Despite four decades of research effort, a therapeutic strategy offering a cure for, or a means of arresting the pathology of PD remains elusive. Established drug-based therapies are essentially palliative and not effective in all patients. Moreover, the side effect profiles of most drugs used in PD account for significant morbidity, especially with chronic use, whilst the efficacy of these treatments inevitably diminishes with time as cell loss proceeds [6]. A need exists, therefore, for a novel therapeutic approach, which is both affordable and more importantly, provides the potential for arresting disease progression as well as ameliorating symptoms. Since apoptotic cell death is almost certainly one of the central components in selective nigrostriatal neuronal death [7-9] future therapeutic strategies could involve the targeted use of bio-molecules with 'anti-apoptotic' properties. Alternatively, a positive therapeutic effect could be produced by molecules with neurotrophic properties or the ability to stimulate neurogenesis of cells with a dopaminergic phenotype. However, for such an approach to have an improved beneficial effect it would be desirable to stabilize the destructive elements which favour neurodegeneration within the nigra. Compounds with antiinflammatory properties could be beneficial in this respect. It has recently been observed that the glucagonlike peptide-1 receptor (GLP-1R) agonist exendin-4 (EX4) shows neurotrophic [10] and 'neuroprotective' [11] properties in cultured PC12 cells subjected to excitotoxic stress. EX-4 - is also able to restore choline acetyl transferase positive cells following ibotenic acid lesions [11]. In addition Perry et al. [12] have found EX-4 to be neuroprotective in a model of neuropathy. These observations have led these authors to suggest that stimulation of GLP1 receptors (GLP-1R's) could be a therapeutic option in neurodegenerative disorders such as PD. Indeed, EX-4 has been shown to have anti-apoptotic properties against a number of pro-inflammatory mediators in pancreatic $\beta$ islet cells [13] which could be seen as indirect support for this suggestion, particularly since neuroinflammation may be a significant causative factor in PD [5]. Very recently it has been observed that EX-4 reverses indicators of NS damage in 6-hydroxydopamine (6-OHDA) lesioned rats when given five weeks after toxin injection [14]. This has been suggested to result from increased neurogenesis originating in the subventricular zone (SVZ) by EX-4 [14]. While clearly an important observation, the relative stability of the lesion at this time following 6-OHDA [15] contrasts with the ongoing hostile environment which prevails in PD patients or at a time point much sooner after neurotoxin administration in animals. Therefore, whether EX-4 mediated recovery would occur under these conditions is as yet unclear. Neuropeptides, such as glial cell derived neurotophic factor, are emerging as potential therapeutic agents in PD [16]. We have recently observed urocortin I (UCN), an endogenous peptide agonist at corticotrophin releasing factor (CRF) receptors with anti-inflammatory properties [17], to be protective in rodent models of PD $[18,19]$. However, neither GDNF or UCN are able to cross the blood brain barrier meaning that they must either be delivered by neurosurgery or appropriate agonists developed and validated. EX-4 is currently in clinical use in patients with type II diabetes and, despite being a peptide with a molecular weight similar to UCN, is readily able to enter the CNS [20]. Here we have studied the effects of EX-4 on behavioral, neurochemical and histological indices of nigrostriatal damage in both the 6-hydroxydopamine (6-OHDA) or lipopolysaccaride (LPS) lesioned rat. Two distinct models of PD were utilized to diminish the possibility that EX-4 is active against a single unique component of either model. We report here a dramatic and potent reversal by EX-4 of established PD-like lesions in the rat which could be of considerable therapeutic significance if reproduced in the clinic.

\section{Materials and methods Materials}

Desmethylimipramine, exendin-4, LPS (serotype E. Coli 0111:B4), pargyline, catalase, L-tyrosine, ferrous ammonium sulphate, benserazide, $6 \mathrm{MPH}_{4}$, 6-OHDA, LPS, apomorphine hydrochloride, 3-iodo-L-tyrosine, D-tyrosine and tyrosine hydroxylase were all obtained from Sigma, UK. Apomorphine and 6-OHDA were dissolved in 2.0\% $\mathrm{w} / \mathrm{v}$ ascorbic acid, whilst UCN solid was initially dissolved in $70 \%$ ethanol and further diluted in saline to $1 \times 10^{-8} \mathrm{M}$ stock concentration. All drugs, apart from LPS and 6OHDA were injected in a volume of $0.1 \mathrm{ml} / 100 \mathrm{~g}$ body weight. Rabbit polyclonal anti-rat TH IgG was obtained from Calbiochem. Horseradish peroxidase (HRP) conjugated goat anti-rabbit IgG was obtained from Cell Signaling, MA. Biotinylated swine anti-rabbit IgG was obtained from Dako, Denmark. ABC complex was purchased from Vector Laboratories, UK. All other reagents were of Analar or HPLC grade.

\section{Surgical procedures}

An overview of the experimental protocols used in the present series of experiments is shown in figure 1. Note 


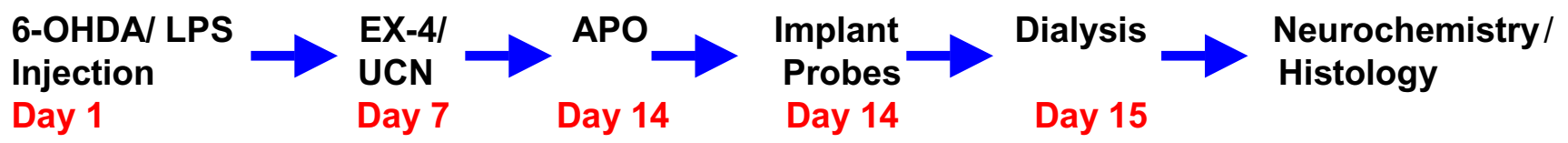

Figure I

Flow diagram of the protocols used in the present study and the sequence in which they were performed. Groups of rats were put through all of the procedures from toxin injection to ex vivo neurochemistry and histology.

that groups of rats went through all the procedures indicated from initial toxin injection to ex vivo neurochemistry and histology. Experiments were carried out in accordance with the Animals (Scientific Procedures) Act UK (1986). Male Wistar rats (210-240 g) were group housed and access to food and water was ad libitum. Care was taken to minimize animal usage and typically, tissue was used in several different assay paradigms. Prior to surgery, animals to be lesioned with 6-OHDA received pargyline (50 $\mathrm{mg} / \mathrm{kg}$, i.p.) and desmethylimipramine (25 mg/kg, i.p.), in order to maximize the selectivity of the toxin for dopaminergic neurons. Animals were anaesthetized with isofluorane ( $4 \%$ for induction, $1.5 \%$ for maintenance), secured in a stereotaxic frame (David Kopf, US) and given injections of 6-OHDA $(8 \mu \mathrm{g} / 4 \mu \mathrm{l}$ of saline with $1 \%$ ascorbic acid) injected into the right medial forebrain bundle (from bregma in mm; A -4.3, L 1.4 and V 8.2) while LPS ( $2 \mu \mathrm{g} / 2 \mu \mathrm{l}$ saline) was injected into the substantia nigra pars compacta ( $\mathrm{SNc}$; from bregma in mm; A -5.2, L 2.2 and $\mathrm{V} 8.3$ ). Seven days later rats were administered EX-4 ( 0.1 or $0.5 \mu \mathrm{g} / \mathrm{kg}$ i.p, twice daily) dissolved in $0.9 \%$ saline for a period of seven days.

\section{Assessment of nigrostriatal lesion severity following apomorphine challenge}

All animals received an apomorphine challenge (APO; 0.5 $\mathrm{mg} / \mathrm{kg} \mathrm{sc}$.) in order to assess lesion severity as previously described [21]. Animals were placed in a circular test arena and following a short period of acclimatization, injected with the dopaminergic agonist. Contraversive turns were noted $20 \mathrm{~min}$. post-injection and recorded over a $120 \mathrm{~s}$ observation period. Only complete, 'tight' turns were recorded. We have tested the value of observing rats for longer periods of time (up to $60 \mathrm{~min}$ ) and recording rotations. Although, obviously, the number of rotations was considerably higher using this protocol the relative difference between groups was virtually identical to sampling for the much shorter time period and the overall methodology was far more time efficient.

\section{In vivo microdialysis}

Later that day rats were implanted with concentric dialysis probes of a construction previously described [22]. Probes were bilaterally implanted into each striatum (from bregma; A +0.2, L 3.0, and ventral 8.2) and the following day perfused with an artificial cerebrospinal fluid (aCSF) solution (composition in mM: $2.5 \mathrm{KCl} ; 125 \mathrm{NaCl} ; 1.18$ $\mathrm{MgCl}_{2} ; 1.26 \mathrm{CaCl}_{2}$ ) as previously used [22] but without addition of the 5-HT reuptake inhibitor citalopram. Following a 1 hour equilibration period four $30 \mathrm{~min}$ 'basal' samples were collected prior to infusion of $100 \mathrm{mM}$ $\mathrm{K}^{+}$containing aCSF to evoke DA release. In the latter case the concentration of $\mathrm{Na}^{+}$was decreased accordingly to maintain osmolarity of the aCSF.

\section{Tissue dopamine assay}

Animals received pargyline $(50 \mathrm{mg} / \mathrm{kg}) 30 \mathrm{~min}$ prior to sacrifice. Brains were removed, striata dissected and homogenized in ice-cold phosphate buffer ( $\mathrm{pH} 7.4)$. All homegenates were split into two equal portions, with one half of each treated with $0.2 \mathrm{M}$ perchloric acid $(1: 10, \mathrm{w} / \mathrm{v})$ containing ascorbic acid $(0.2 \mu \mathrm{M})$ and EDTA $(0.2 \mu \mathrm{M})$, to precipitate cell debris. These were then centrifuged at $9000 \times \mathrm{g}$ for $15 \mathrm{~min}$ at $4^{\circ} \mathrm{C}$, supernatants passed through a syringe filter $(10 \mu \mathrm{m}$ pore size) and whole tissue dopamine levels estimated using HPLC with electrochemical detection [22]. Brain blocs containing nigra were rapidly frozen and retained for immunohistochemistry.

\section{Ex vivo tyrosine hydroxylase assay}

$\mathrm{TH}$ activity was measured in the remaining homogenates, using a modification of the method of Naoi et al. [23]. Aliquots were incubated with $200 \mu \mathrm{M}$ L-tyrosine in a total reaction mixture volume of $100 \mu$ l. This consisted of the following components: $100 \mathrm{mM}$ sodium acetate-acetic acid buffer ( $\mathrm{pH}$ 6.0), $2 \mathrm{mM}$ ferrous ammonium sulphate, $1 \mathrm{mM} \mathrm{MPH}_{4}, 10 \mu \mathrm{g}$ of catalase and $1 \mathrm{mM}$ benserazide, an inhibitor or aromatic L-amino acid decarboxylase (AADC). $6 \mathrm{MPH}_{4}$ solution was firstly made as $10 \mathrm{mM}$ in 1 $M$ mercaptoethanol. The incubation mixture, except for tyrosine and the pteridin cofactor, was preincubated with homegenates at $37^{\circ} \mathrm{C}$ for $5 \mathrm{~min}$, and the reaction was initiated by addition of the L-tyrosine and $6 \mathrm{MPH}_{4}$. After incubation at $37^{\circ} \mathrm{C}$ for $10 \mathrm{~min}$, the reaction was terminated by addition of $100 \mu \mathrm{l}$ perchloric acid $(0.1 \mathrm{M}$, containing $0.4 \mathrm{mM}$ sodium metabisulphite and $0.1 \mathrm{mM}$ disodium EDTA). The sample was then vortexed and left to stand on ice for $10 \mathrm{~min}$, then centrifuged at $1000 \times \mathrm{g}$ for $10 \mathrm{~min}$. The supernatant was diluted to 1 in 1000 with mobile phase, then analyzed using HPLC-ED to measure 
the amount of L-DOPA. As blank, a similar reaction mixture containing D-tyrosine instead of the L-isomer and $100 \mu \mathrm{M}$ 3-iodo-L-tyrosine was used [23].

\section{Immunohistochemistry}

Slide-mounted $10 \mu \mathrm{m}$ cryostat sections from flash-frozen rat brain blocs were removed from the freezer and allowed to equilibrate to room temperature for 30 minutes, prior to post fixation in $4 \%$ paraformaldehyde, containing $1 \%$ gluteraldehyde for 5 minutes at $0^{\circ} \mathrm{C}$. Following rinsing in $0.1 \mathrm{M}$ PBS for 5 minutes, sections were dehydrated through graded alcohols and endogenous peroxidase activity was blocked by incubation in $0.3 \% \mathrm{H}_{2} \mathrm{O}_{2}$ in methanol for 10 minutes. The sections were then rehydrated and non-specific immunoreactivity was blocked with $10 \%$ swine serum in PBS for 10 minutes. Sections were then incubated in primary antibody (rabbit anti-rat TH IgG) at 1:700 in PBS for 16 hours at $4^{\circ} \mathrm{C}$. After rinsing, the sections were incubated sequentially in biotinylated swine anti-rabbit antibody 1:250 in PBS (Dako, Denmark) for 30 minutes at room temperature and $\mathrm{ABC}$ complex following the manufacturer's instructions. Immunoreactivity was visualized through incubation in $0.5 \mathrm{mg} / \mathrm{ml}$ 3-diaminobenzidine (DAB), containing $0.009 \% \mathrm{H}_{2} \mathrm{O}_{2}$ for 2 minutes at room temperature. The sections were counterstained in Harris haematoxylin, dehydrated, cleared and mounted for microscopic examination. Sections were viewed under light microscopy ( $\times 40$ magnification). Digital images were captured using a Leica DC500 system and the manufacturer's software. For each animal, six successive nigral sections were selected from both treated and contralateral side, taken from a starting point of $-5.5 \mathrm{~mm}$ relative to bregma, using a total of six rats per group.

\section{Data handling and analysis}

Data obtained from apomorphine challenge, whole tissue DA and TH assay studies were expressed as mean values \pm S.E.M. Data were subjected to one way or two way ANOVA to identify overall trends, with a post hoc Bonferroni's multiple comparison test used to establish significant differences between the groups. Statistical analysis was performed using a proprietary software package (GraphPad Prism ${ }^{\mathrm{TM}}$ ). Numbers of animals used in experiments are detailed in the figure legends. In all cases, comparisons were made with respect to toxin/vehicle values. Statistical significance was set at $\mathrm{p}<0.05$.

\section{Results}

Apomorphine (APO) induced circling is regarded as a quantitative index of NS lesion severity [21] and thus, an attenuation is predictive of potential anti-parkinsonian activity. Our findings reveal that tight contralateral circling was clearly evident in 6-OHDA and LPS treated rats, but this was dose-dependently attenuated by EX-4 (Fig.
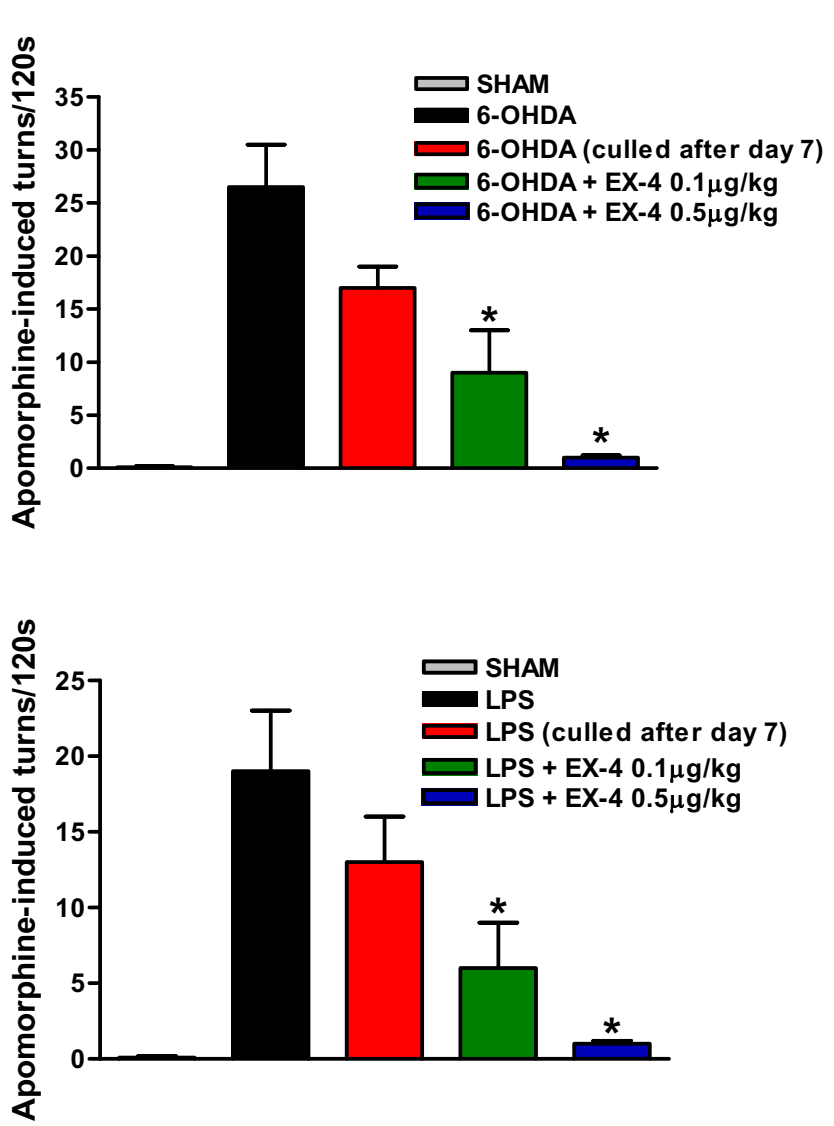

\section{Figure 2}

Effect of EX-4 $(0.1$ and $0.5 \mu \mathrm{g} / \mathrm{kg})$ on apomorphine-induced rotational behaviour in 6-OHDA (upper panel) or LPS (lower panel) lesioned rats. EX-4 was administered twice daily for seven days seven days after toxin injection. Circling was measured for $120 \mathrm{~s} 30 \mathrm{~min}$ after apomorphine injection. One way ANOVA values were 14.90, $p<0.001$ (6-OHDA) and 16.24, $\mathrm{p}<0.00 \mathrm{I}$ (LPS). *indicates significant differences from $\mathrm{UCN}$ or sham injection sites $(\mathrm{p}<0.0 \mathrm{I}, \mathrm{n}=6$ per group $)$.

2). Note that lesions are already well-advanced seven days post injection [Fig. 2; [18,19]].

Striatal tissue DA concentration was substantially reduced in 6-OHDA/LPS treated rats compared with sham or EX-4 groups (Fig. 3). This clearly indicates that EX-4 promotes the retention or restoration of DA cells or cells with a dopaminergic phenotype. In order to estimate functional integrity of nigral neurons ipsilateral to injection sites, we measured L-dihydroxyphenylalanine (L-DOPA) synthetic capacity of striatal homogenates as well as tissue DA content. Ex vivo TH activities were significantly reduced in striata of 6-OHDA and LPS treated rats when compared to sham treated rats and this was in marked contrast with animals treated with both EX-4 doses, in which TH activities were near to control values (Fig 4). 

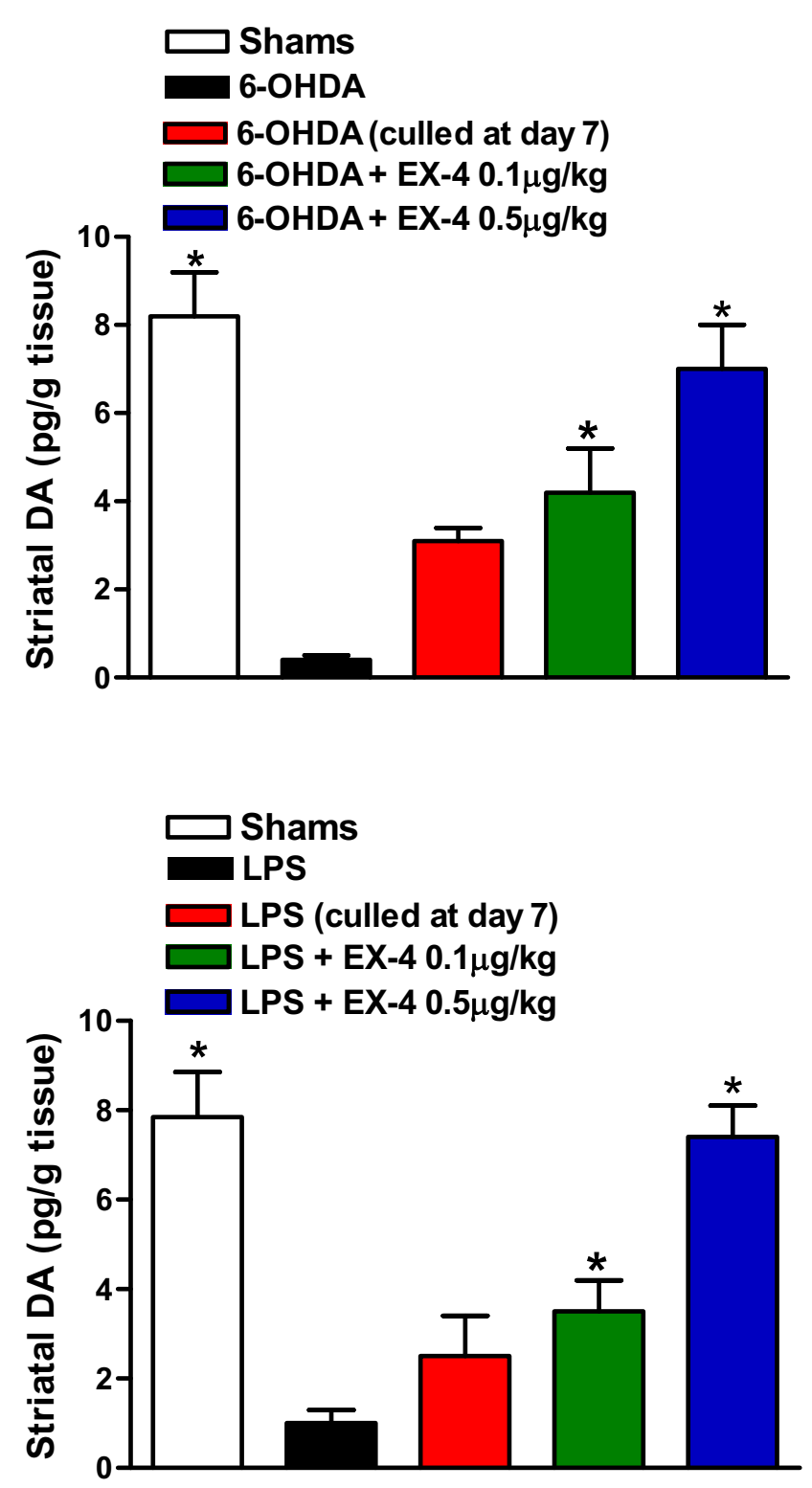

Figure 3

Effect of EX-4 $(0.1$ and $0.5 \mu \mathrm{g} / \mathrm{kg})$ on striatal tissue DA content in 6-OHDA (upper panel) or LPS (lower panel) lesioned rats. EX-4 was administered twice daily for seven days seven days after toxin injection. One way ANOVA values were 7.88, $\mathrm{p}<0.00$ I (6-OHDA) and 6.67, $\mathrm{p}<0.00$ I (LPS). *indicates significant differences from EX-4 or sham injection sites ( $\mathrm{p}<0.0 \mathrm{I}, \mathrm{n}=6$ per group).

Having established that administration of EX-4 prevents the loss of NS function post-toxin in both rodent models, we needed to ascertain whether this could be explained by preservation of discrete nigral cells or alternatively achieved through a substantial upregulation of TH protein in surviving cells. In order to test these possibilities, we stained cryopreserved brain sections for TH immunoreac-
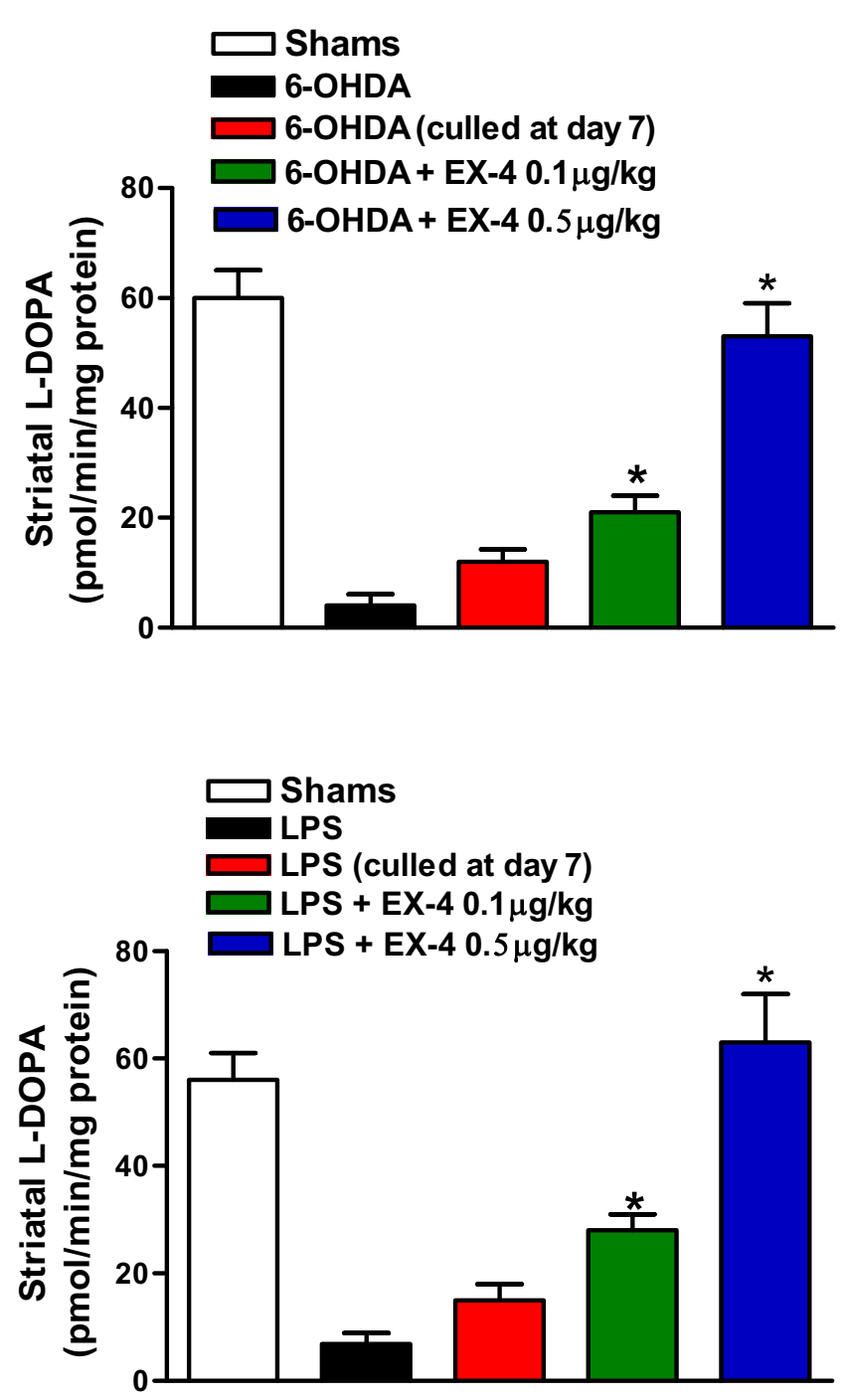

Figure 4

Effect of EX-4 (0.I and $0.5 \mu \mathrm{g} / \mathrm{kg})$ on striatal tissue TH activity in 6-OHDA (upper panel) or LPS (lower panel) lesioned rats. EX-4 was administered twice daily for seven days seven days after toxin injection. One way ANOVA values were 7.88, $\mathrm{p}<0.001$ (6-OHDA) and 6.67, $\mathrm{p}<0.00$ I (LPS). *indicates significant differences from EX-4 or sham injection sites ( $\mathrm{p}<0.0 \mathrm{I}, \mathrm{n}=6$ per group).

tivity and counted nigral cell bodies in the substantia nigra. As shown in figures 5 and 6, 6-OHDA or LPS treatment resulted in a near complete loss of $\mathrm{TH}+$ cell bodies, with very few accompanying dendrites remaining (Figures show contralateral and ipsilateral nigral slices from the same section). Rats similarly treated, but sacrificed after 7 days show a more modest loss of both NS cell bodies compared to 14 day exposure $[18,19]$. As can be clearly seen, EX-4 almost completely protected against loss of $\mathrm{TH}^{+}$cells when administered seven days following 6-OHDA or LPS 

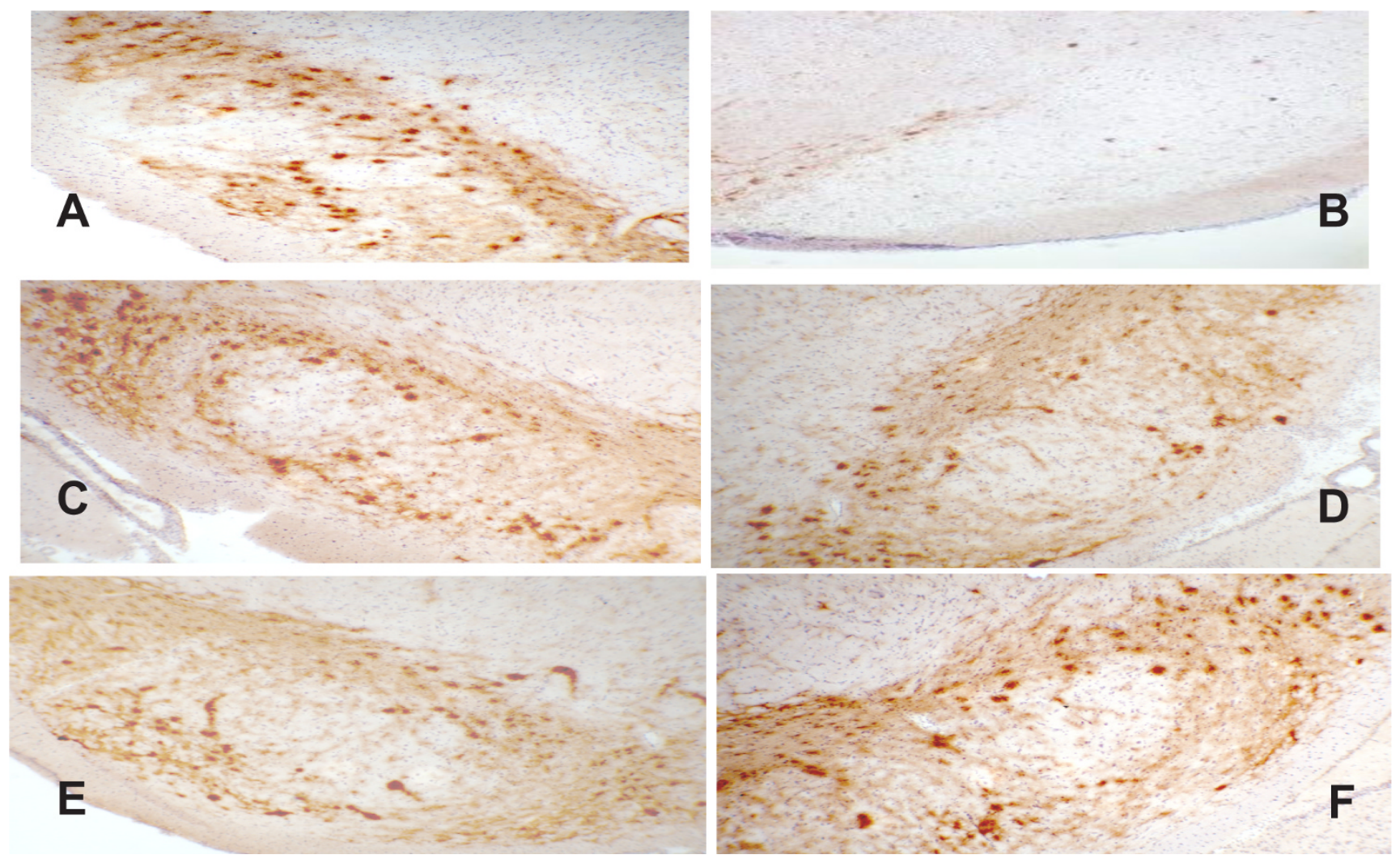

\section{Figure 5}

Photomicrographs of selected rat nigral sections, immunostained for TH. Nigrostriatal cell bodies and dendrites appear dark brown/brown in sections. Sections A, C, E and are contralateral (untreated) nigra for comparison with ipsilateral (treated) nigra B, D, F. Key: B - 6-OHDA + vehicle, D - 6-OHDA + EX-4 0.I $\mu \mathrm{g} / \mathrm{kg}, \mathbf{F}-6-\mathrm{OHDA}+\mathrm{EX}-4 \mathrm{0.5} \mu \mathrm{g} / \mathrm{kg}$. Bar is I00 $\mu \mathrm{m}$. Sections are representative of 6 rats for each treatment.

injection and this was particularly marked in rats given LPS and the higher dose of EX-4. We are unclear as to the reason for this other than to speculate that it may be the result of the toxin used.

In order to evaluate the effect of EX-4 on extracellular DA in the striatum we employed microdialysis in freely moving rats. We have assumed that extracellular DA represents a functional index of DA release and this is supported by our observation that $1 \mu \mathrm{M}$ tetrodotoxin infusion decreased dialysate DA by over $90 \%$ in sham treated rats (data not shown). Both 6-OHDA and LPS greatly reduced extracellular DA (Fig 7), which in a number of samples fell below the limit of detection. In these cases we have assigned a value of $5 \mathrm{fmol} / 10 \mu \mathrm{l}$, which constitutes the level at which an unambiguously identifiable DA peak can be resolved, in order to facilitate analysis of the data. EX-4 dose-dependently reversed the depletion of extracellular DA resulting from either 6-OHDA or LPS (Fig. 7). This restoration of basal and evoked DA release indicates a functional basis upon which motor movement is normalized in apomorphine treated rats (Figs. 2 and 7).

\section{Discussion}

We have used a variety of measures, behavioural, neurochemical and histological which indicate a clear protective role for EX-4 against 6-OHDA or LPS mediated nigrostriatal lesions. These findings support a potential protective role for EX-4 in these two paradigms of PD and clearly demonstrate that when EX-4 is given after either 6-OHDA or LPS, a comprehensive reversal of all selected markers of nigrostriatal cellular loss results. This suggests that EX-4 is able to rescue dopaminergic neurons once damage is established or possibly stimulate neurogenesis of cells with a dopaminergic phenotype. Of particular significance is our finding that EX-4 is able to arrest and possibly reverse NS lesions, once the neurodegenerative process has commenced. This principle (if reproduced in the human brain) would have obvious clinical significance since patients generally present with symptoms only once 

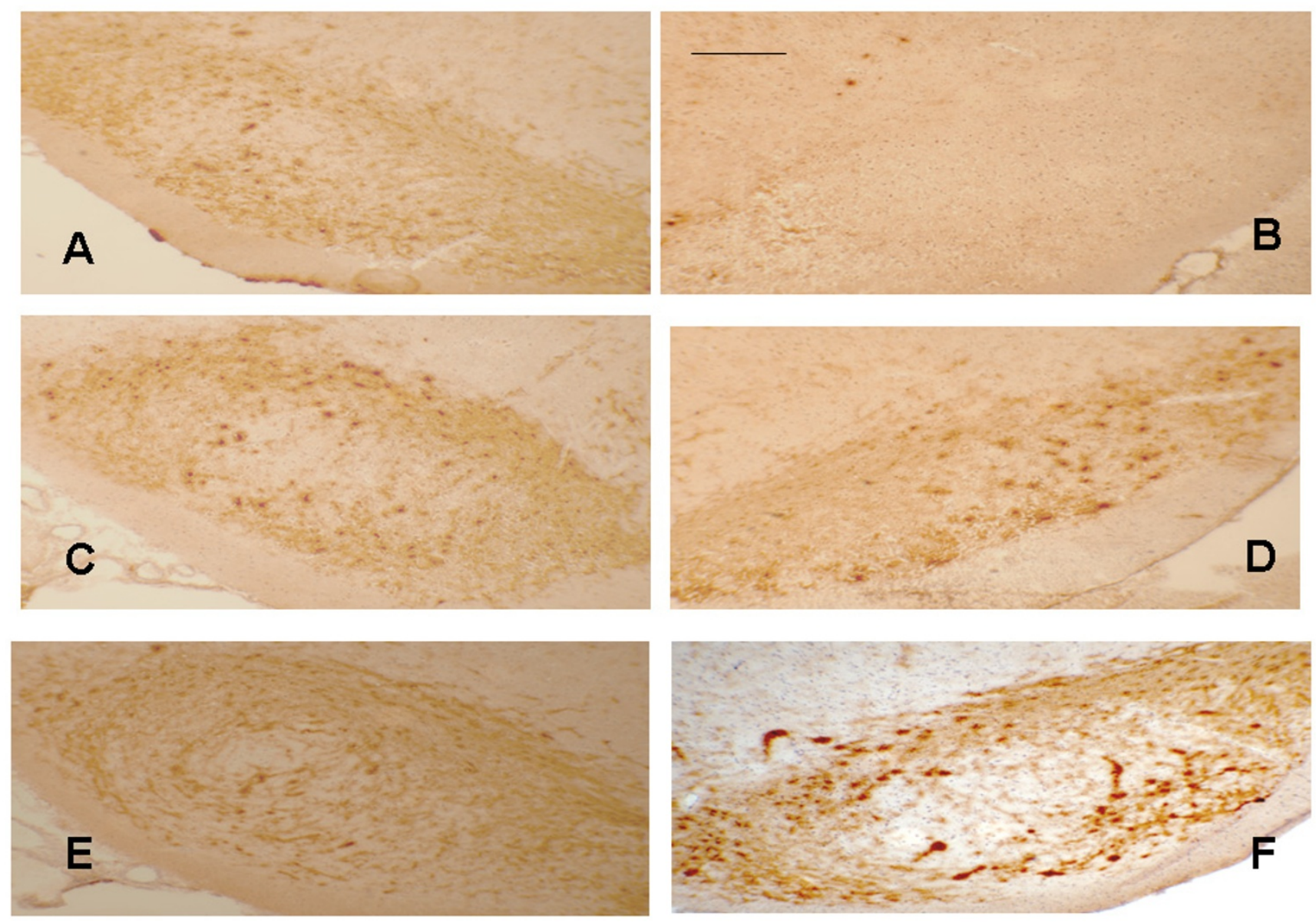

\section{Figure 6}

Photomicrographs of selected rat nigral sections, immunostained for TH. Nigrostriatal cell bodies and dendrites appear dark brown/brown in sections. Sections A, C, E and are contralateral (untreated) nigra for comparison with ipsilateral (treated) nigra B, D, F. Key: B - LPS + vehicle, D - LPS + EX-4 0.I $\mu \mathrm{g} / \mathrm{kg}$, F - LPS + EX-4 $0.5 \mu \mathrm{g} / \mathrm{kg}$. Bar is $100 \mu \mathrm{m}$. Sections are representative of 6 rats for each treatment.

nigral neuronal loss reaches $70-80 \%$ of the total nigral compliment, and striatal DA levels have fallen significantly [24]. In the present study, EX-4 appears to 'reverse' loss of $\mathrm{TH}+$ immunoreactivity, since sections taken from rats culled 7 days post-6-OHDA or LPS clearly show greater numbers of $\mathrm{TH}+$ structures than those from rats killed 14 days after toxin injection $[18,19]$.

The underlying cellular mechanism(s) responsible for our finding is as yet, unclear, but other studies $[10,11]$ suggest that increased production of cAMP following GLP-1R stimulation occurs. It has previously been reported that EX-4 has anti-apoptotic properties thereby protecting pancreatic $\beta$-cells against pro-inflammatory insults. This may be a significant finding in relation to PD since apoptosis is an important mechanism in 6-OHDA neurotoxicity
[25] and human PD [7] and a role for neuroinflammation in both animal models and PD itself is increasingly apparent $[4,5]$. The use of the single-dose LPS PD model [26] therefore increases the significance of our data. The effects of EX-4 appear to be selectively directed towards the ipsilateral lesioned side as the contralateral side showed no obvious differences in the degree of TH staining between saline and EX-4 treated rats and we have not found any effect of EX-4 on TH staining in naïve rats (data not shown). Moreover, in vitro estimation of DA formation from L-DOPA in naïve rats treated for 7 days with EX-4 were very similar to untreated rats, further indicating a lack of effect of the peptide on TH expression under these conditions (data not shown). It is possible that EX-4 is instigating de novo neurogenesis, presumably from recruited stem cells, as has been postulated in other stud- 

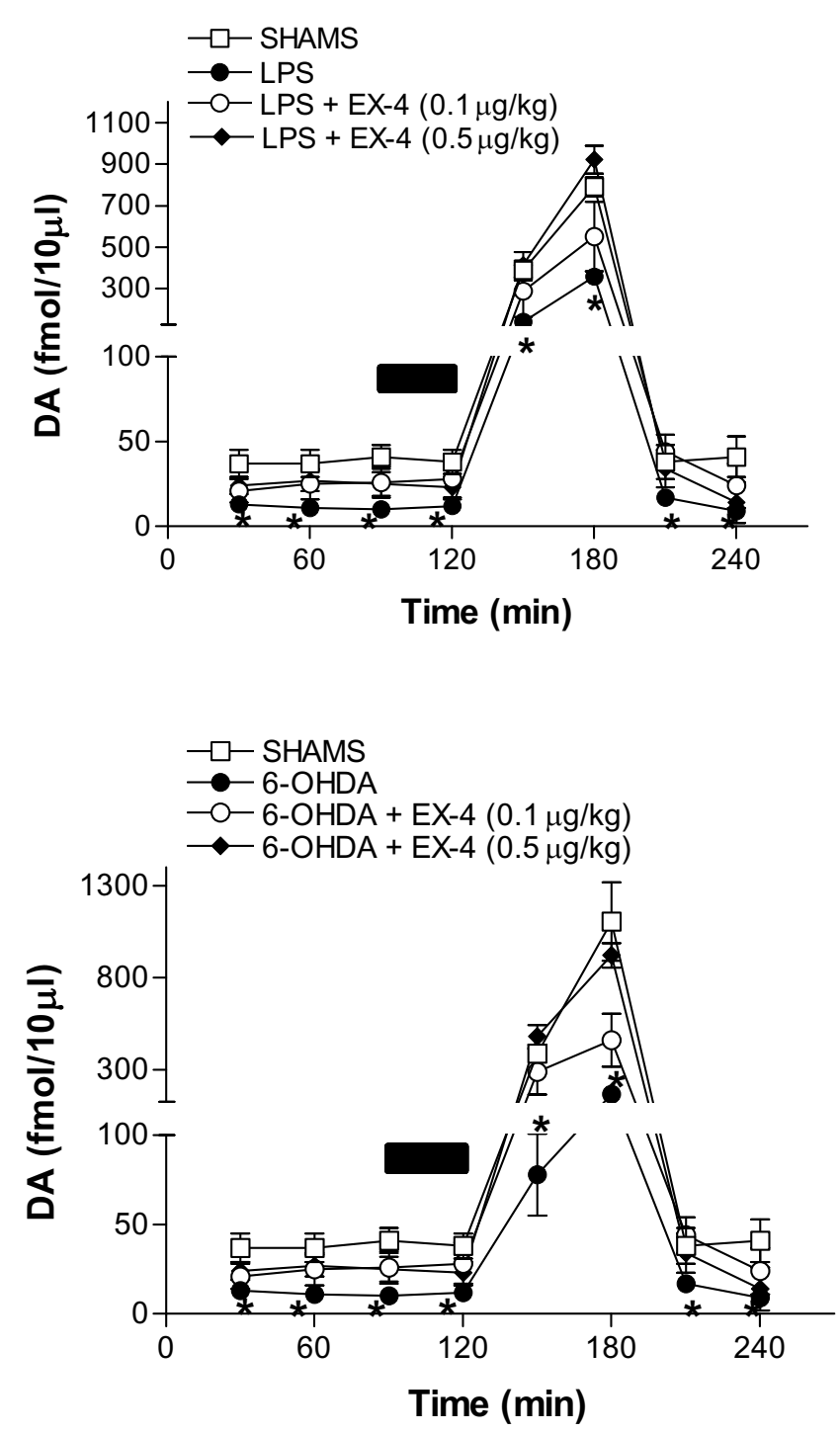

Figure 7

Effect of EX-4 on striatal extracellular DA in 6-OHDA (upper panel) and LPS (lower panel) lesioned rats. The bar indicates the period of $100 \mathrm{mM} \mathrm{K}^{+}$infusion. Two way ANOVA between treatments were $F=6.16$ and 8.77 between treatments and 156.3 and 187.6 over time in 6OHDA and LPS treated groups respectively. *Denotes differences from sham or EX-4 co-treated rats using Bonferonni's multiple comparison test post hoc. ( $p<0.05, n=6$ per group).

ies [14,27], however, this is clearly speculative and requires futher detailed investigation. The precise neuroanatomical site at which EX-4 acts is therefore as yet unclear and studies, which we are currently undertaking, on the cellular location of GLP1R's in both rodents and patients are needed to shed further light on this.

\section{Conclusion}

Overall, our results significantly add to a growing knowledge base, whereby EX-4 mediates a functional neuroprotection $[10-12,14]$ with the crucial refinement that we have demonstrated, for the first time, efficacy in two distinct in vivo models of a currently incurable neuropathology. The apparent ability of EX-4 to arrest NS damage and possibly stimulate remaining cells, suggests a novel mechanism, which if translated therapeutically would offer a significant advance in PD treatment. This principle has recently been proposed as an essential prerequisite for the basis of a meaningful advance in PD therapy [28]. Vitally, EX-4 has a long plasma half life compared with endogenous GLP-1 [20], readily crosses the blood brain barrier and is in current clinical use. This suggests that EX-4 could, in principal, be trialed in PD patients with relatively little delay.

\section{Abbreviations}

DA: dopamine; EX-4: exendin-4; GLP-1: glucagon-like peptide 1; GLP-1R: glucagon-like peptide 1 receptor; LPS: lipopolysaccharide; 6-OHDA: 6-hydroxydopamine; TH: tyrosine hydroxylase; SNc: Substantia nigra pars compacta.

\section{Competing interests}

The authors declare that they have no competing interests.

\section{Authors' contributions}

$\mathrm{AA}, \mathrm{AH}, \mathrm{AK}$ and PSW were responsible for the planning and actual experimentation involved in this study. RL and CSB contributed to the interpretation of the data and writing of the manuscript. The manuscript was read and approved by all of the authors.

\section{Acknowledgements}

Mr Amjad Abuirmeileh is supported by a doctoral grant from the Al Isra Private University, Amman, Jordan. The work was supported by the Parkinson's Disease Society of Great Britain.

\section{References}

I. Clark D, White FJ: Review: DI dopamine receptor $\mathbf{B}$ the search for a function: a critical evaluation of the DI/D2 dopamine receptor classification and its functional implications. Synapse 1987, I:347-388.

2. Vaux DL, Korsmeyer SJ: Cell death in development. Cell 1999 , 96:245-254.

3. Gandhi S, Wood NW: Molecular pathogenesis of Parkinson's disease. Hum Mol Genet 2005, I 4:2749-2755.

4. Block ML, Zecca L, Hong J-S: Microglia-mediated neurotoxicity: Uncovering the molecular mechanisms. Nature Neurosci 2007, 8(I):57-69.

5. Whitton PS: Inflammation as a potential causative factor in the aetiology of Parkinsons disease. Br J Pharmacol 2007, I 50:963-976.

6. Hurtig HI: Problems with current pharmacological treatment of Parkinson's disease. Exp Neurol 1997, I44:10-16.

7. Tatton NA, Maclean-Fraser A, Tatton WG, Perl DP, Olanow CW: A fluorescent double-labeling method to detect and confirm apoptotic nuclei in Parkinson's disease. Ann Neurol 1998, 44:SI 42-I48. 
8. Ochu EE, Rothwell NJ, Waters CM: Caspases mediate 6-hydroxydopamine induced apoptosis but not necrosis in PCI 2 cells. J Neurochem 1998, 70:2637-2640.

9. Schapira AH: Causes of neuronal death in Parkinson's disease. Adv Neurol 200I, 86: I55-162.

10. Perry T, Lahiri DK, Chen D, Zhou J, Shaw KTY, Egan JM, Grieg NH: A novel neurotrophic property of glucagons-like peptide I: a promoter of nerve cell growth factor mediated differenciation in PCI 2 cells. J Pharmacol Exp Ther 2002, 300:958-966.

II. Perry TA, Haughey NJ, Mattson MP, Egan JM, Grieg NH: Protection and reversal of excitotoxic neuronal damage by glucagonlike peptide-I and exendin-4. J Pharmacol Exp Ther 2002, 302:881-888.

12. Perry TA, Holloway HW, Weerasuriya A, Mouton PR, Duffy K, Mattison JA, Grieg NH: Evidence of GLp-I-mediated neuroprotection in an animal model of pyridoxine-induced peripheral sensory neuropathy. Exp Neurol 2007, 203:293-30I.

13. Li L, El-Kholy W, Rhodes CJ, Brubaker PL: Glucagon-like peptideI receptor signaling modulates beta cell apoptosis. J Biol Chem 2003, 278:47|-478.

14. Bertilsson G, Patrone C, Zachrisson O, Andersson A, Dannnaeus K, Heidrich J, Kortesmaa J, Mercer A, Neilsen E, Ronnholm H, Wilkstrom L: Peptide hormone exndin-4 stimulates subventricular zone neurogenesis in the adult rodent brain and induces recovery in an animal model of parkinson's disease. J Neurosci Res 2008, 86:326-38.

15. Zuch CL, Nordstroem VK, Briedrick LA, Hoernig GR, Granholm AC Bickford PC: Time course of degenerative alterations in nigral dopaminergic neurons following a 6-hydroxydopamine lesion. J Comp Neurol 2000, 427:440-454.

16. Yasuhara T, Shingo T, Date I: Intracerebral transplantation of genetically engineered cells for Parkinson's disease: toward clinical application. Cell Transplant 2007, 16:125-I32.

17. Gonzalez-Rey E, Fernandez-Martin A, Chomy A, Delgado M: Therapeutic effect of urocortin and adrenomedullin in a murine model of Crohn's disease. Gut 2006, 55:824-32.

18. Abuirmeileh A, Lever R, Kingsbury AE, Lees AJ, Locke IC, Knight RA, Chowdrey HS, Biggs CS, Whitton PS: The corticotrophin releasing factor-like peptide urocortin reverses key deficits in two rodent models of Parkinson $\mathbf{=} \mathbf{s}$ disease. Eur J Neurosci 2007 26:417-423.

19. Abuirmeileh A, Harkavyi A, Lever R, Biggs CS, Whitton PS: Urocortin, a CRF-like peptide, restores key indicators of damage in a neuroinflammatory model of Parkinson's disease. J Neuroinflammation 2007, 4: 19 .

20. King $A B$, Wolfe $G$, Healy S: Clinical observations of exenatide treatment. Diabetes Care 2006, 29:1984.

21. Ungerstedt U: Postsynaptic supersensitivity after 6-hydroxydopamine induced degeneration of the nigro-striatal dopamine system. Acta Physiol Scand Suppl 1971, 367:8993.

22. Biggs CS, Fowler LJ, Pearce BR, Whitton PS: Regional effects of sodium valproate on extracellular concentrations of 5 hydroxytryptamine, dopamine and their metabolites in the rat brain: An in vivo microdialysis study. J Neurochem 1992, 59: $1702-1708$.

23. Naoi M, Takahashi T, Nagatsu T: Simple assay procedure for tyrosine hydroxylase activity by high-performance liquid chromatography employing coulometric detection with minimal sample preparation. J Chromatogr 1988, 427:229-38.

24. Abercrombie ED, Bonatz AE, Zigmond MJ: Effects of L-dopa on extracellular dopamine in striatum of normal and 6-hydroxydopamine-treated rats. Brain Res 1990, 525:36-44.

25. Cutillas B, Espejo M, Gil J, Ferrer I, Ambrosio S: Caspase inhibition protects nigral neurons against 6-OHDA-induced retrograde degeneration. Neuroreport 1999, 10:2605-2608.

26. Herrera AJ, Castano A, Venero JL, Cano J, Machado A: The single intranigral injection of LPS as a new model for studying the selective effects of inflammatory reactions on the dopaminergic system. Neurobiol Dis 2000, 7:429-447.

27. Borta A, Hoglinger GU: Dopamine and adult neurogenesis. I Neurochem 2007, 100:587-595.

28. Meissner WT, Hill MP, Tison F, Gross CE, Bezard E: Neuroprotective strategies for Parkinson's disease: conceptual limits of animal models and clinical trials. Trends Pharmacol Sci 2004, 25:249-253.
Publish with Biomed Central and every scientist can read your work free of charge

"BioMed Central will be the most significant development for disseminating the results of biomedical research in our lifetime. "

Sir Paul Nurse, Cancer Research UK

Your research papers will be:

- available free of charge to the entire biomedical community

- peer reviewed and published immediately upon acceptance

- cited in PubMed and archived on PubMed Central

- yours - you keep the copyright 